\title{
Study of Odontometric Parameters in Gender Identification
}

Pagare $\mathrm{N}^{1}$, Chourasiya $\mathrm{S}^{2 *}$ and Dedhia $\mathrm{H}^{3}$

${ }^{1}$ Department of Forensic Science, Institute of Forensic

Science Mumbai, India

${ }^{2}$ Department of Forensic Science, Guru Ghasidas

Vishwavidyalaya, India

${ }^{3}$ Department of Forensic Science, Institute of Forensic Science Mumbai, India

*Corresponding author: Shivam Chourasiya, Department of Forensic Science, Guru Ghasidas Vishwavidyalaya, Bilaspur (C.G.), India

Received: March 09, 2017; Accepted: April 25, 2017; Published: May 05, 2017

\begin{abstract}
Forensic Odontology is a branch of forensic medicine that in the interest of justice deals with dental evidence presented in the courts of law. The basis that Forensic odontology has gained wide acceptance in the field of criminal justice is because no two people have identical teeth. Bite mark pattern was analyzed to study the odontometric measurements like mieso-distal incisor width and inter canine ratio and to check for the presence of sexual dimorphism between ages of 16-25. A total of 40 samples i.e. 20 males and 20 females were considered for the study. Their class and individual characteristics were also noted. In the present study, on the basis of odontometric parameters like arch length and inter canine ratio sexual dimorphism in males and females can be determined. Also, the study revealed class characteristics and the individual characteristics i.e. odontometric parameters.
\end{abstract}

Keywords: Forensic; Odontology; Bite mark; Odontometric parameter; Sexual dimorphism

\section{Introduction}

Human identification is the foundation of civilization, and the unique features of the teeth and jaws has been used since Roman times for the identification of unknown individuals. Teeth being the hardest and chemically the most stable tissue, which exhibit the least turnover of natural structure in the body are selectively preserved and fossilized, thereby providing by far the best record for evolutionary change $[1,2]$. Their stability in the face of fire and bacterial decomposition makes them very useful, excellent material in living and non living populations for anthropological, genetic, odontological, forensic investigations, and identification [3,4]. Also, since the human dentition has a complement of 32 teeth, at least a few teeth are usually recovered. Hence, they are regularly used in comparative identification of human remains. The benefits of determining sex from odontometric features are simple, inexpensive, consistent, and easy to perform $[5,6]$. Sex estimation constitutes an important step in building a post-mortem profile, and correct sex identification limits the pool of missing persons to just one half of the population $[7,8]$. The precision of sexing using different parameters of the body such as craniofacial morphology and measurements on the pubis ranges from $96 \%$ to $100 \%$. Considering the fact that most teeth complete development before skeletal maturation makes them a useful adjunct as a sex indicator, particularly in young individual's dentition. Sexual dimorphism represents a group of morphologic characteristics that differentiate a male from a female $[9,10,11]$. Among these morphological differences, tooth size has been estimated in various populations between males and females for its applicability in anthropologic and forensic investigations to classify the gender from dental remains. Mandibular canines considered as "key teeth" for personal identification are found to exhibit the greatest sexual dimorphism amongst all the teeth with mean age of eruption of 10.87 years, less affected than other teeth by periodontal diseases, the last teeth to be extracted with respect to age and also better likely to survive severe trauma such as air disasters, hurricanes, or conflagration [12,13,14]. Identification of sex using skeletal remains presents a great problem to forensic experts especially when only fragments of the body are recovered. In forensic identification, the mouth allows for a myriad of possibilities [15]. Forensic dentists can assist other experts to determine sex of the remains by using teeth and skull. Various features of teeth, like morphology, crown size, root lengths etc. are characteristic for male and female sexes $[16,17,18]$. There are also differences in the skull patterns. These will help a forensic odontologist to identify the sex. New developments like PCR amplification etc. will assist in exactly determining the sex of the remains. Forensic odontology plays an vital important role in determining the sex of victims with bodies mutilated beyond recognition due to major mass disasters, sexual assault or murder cases $[19,20]$. This Pilot study consists of Five odontometric parameters Arch length, Number of Teeth, Incisorial width, Inter canine distance, Inter canine ratio, and these parameter gave the characteristic differentiate between the Bite mark pattern of Male and Female.

In the above context following objectives were satisfied with the help of these Odontometric Parameters.

1. To simulate a dental impression in males and females of age 16-25 for creating a bite mark pattern.

2. To study the sexual dimorphism using odontometric measures (metric system).

3. To study the class and individual characteristics for individual identification.

\section{Materials and Methods}

The study consisted of 40 subjects from Mumbai. After obtaining informed consent, impression of maxillary and mandibular arch was made on modeling wax for purpose of interpretation. Selection 


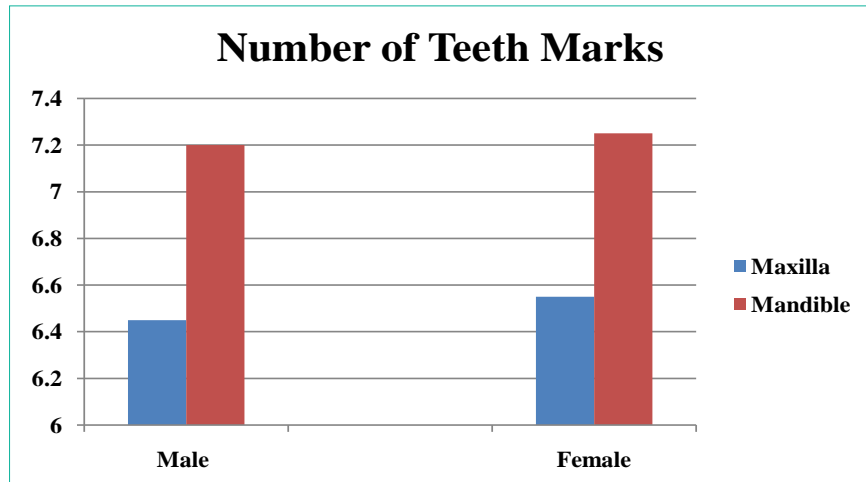

Figure 1: The graph showing number of tooth marks was more in the mandibular arch than the maxillary arch. However, the total number of tooth marks found was not dependent on the gender.

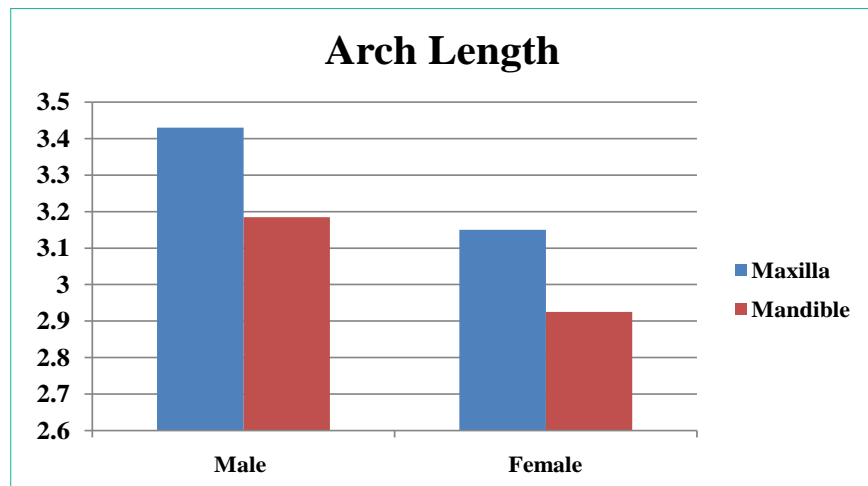

Figure 2: The graph showing arch length was found to be higher in males than that of the females. Also, the maxillary arch length was found to be greater than the Mandibular arch length.

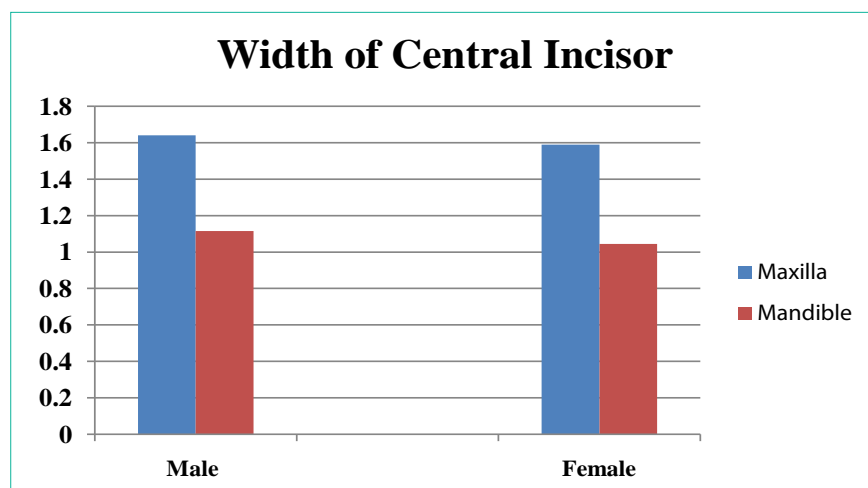

Figure 3: The graph showing width of incisors was found to be more in maxilla than in mandible with no significant sexual dimorphism in males and females.

criteria were the subjects within age group of 16-25. Impressions of Maxillary and Mandibular arches of 40 individuals participating in the study were made and wax study models prepared on modeling wax. Overlay production was done manually. In manual method a sheet of transparency film and a fine tipped pen were used to mark the perimeter of the biting surface. The transparent sheet was directly placed over the biting edges of the wax model. Then with the help of a black fine tipped marker the biting edges were traced. Both the Maxillary and Mandibular models were traced individually in horse shoe shape pattern to simulate a human bite. The odontometric measurements studied are as follows:
1. Arch length: Size/length of each bite mark pattern i.e. singular arch of either maxilla or mandible was measured and recorded in the study table using a Vernier caliper by measuring length from one end to other end of the arch.(the whole arch was considered).

2. Number of teeth: The total number of teeth found on the sample bite mark was noted.

3. Incisorial width: The width of central incisors of maxilla and mandible was measured using a Vernier caliper

4. Inter canine distance: The distance between the two canines was measured using a Vernier caliper for both the maxillary and Mandibular arches.

5. Inter canine ratio: The ratio of maxillary inter canine distance and mandibular inter canine distance was calculated.

\section{Result and Discussion}

The study revealed that the traced bite mark patterns could be used to match the sample bite marks and measurements could be carried out of the odontometric parameters like number of tooth marks, arch length, central incisor width, inter canine ratio. The number of tooth marks was more in the Mandibular arch than the maxillary arch. However, the total number of tooth marks found was not dependent on the gender (Figure 1). The arch length was found to be higher in males than that of the females. Also, the maxillary arch length was found to be greater than the Mandibular arch length (Figure 2). The width of incisors was found to be more in maxilla than in mandible with no significant sexual dimorphism in males and females (Figure 3). The Inter canine distance was found to be more in Male maxilla and mandible than Female (Figure 4). Inter canine ratio was higher in males than in females (Figure 5,6). Every bite mark is unique as it involves unique features like shape of arch, arch length, number of tooth marks, width of incisors, inter canine ratio, arrangement of teeth, etc. These features are different for every individual.

\section{Conclusion}

Human identification is important in cases which involve bite marks and also in cases where other evidences are lost or unavailable. Some odontometric parameters have proven to be good investigative tools for identification. The study revealed that number of tooth marks in the Mandibular arch is more than that of the maxillary arch. The arch length and width of incisors of maxilla is more than

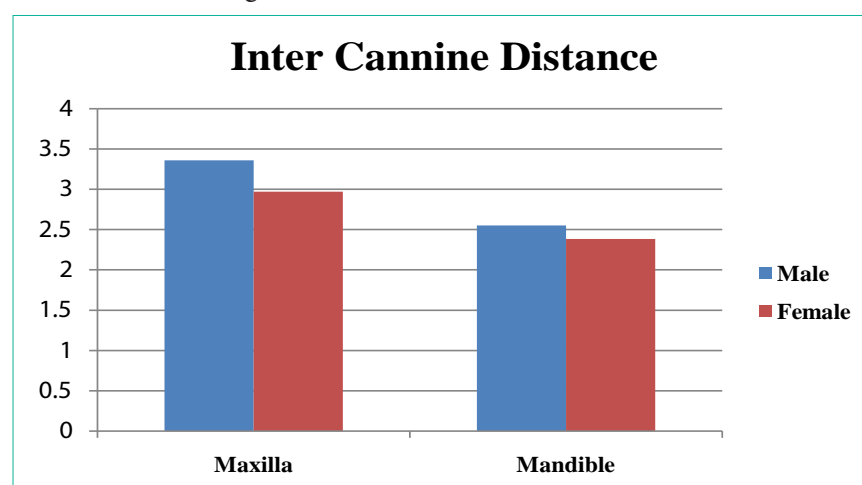

Figure 4: The graph showing Inter canine distance was found to be more in male maxilla and mandible than female with significant sexual dimorphism in males and females. 


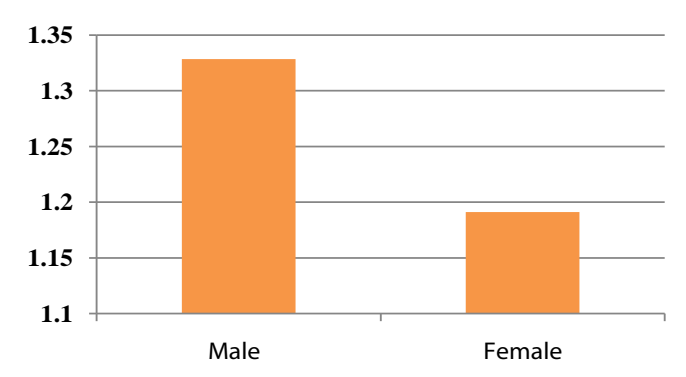

\section{Inter Cannine Ratio}

Figure 5: The graph showing Inter Canine Ratio was significantly higher in males than in females.

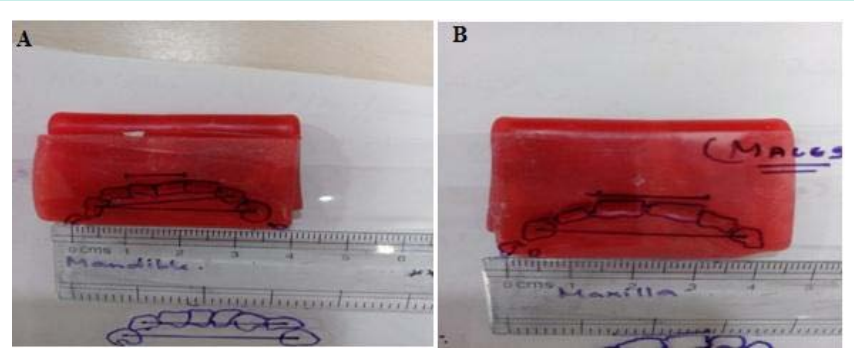

Figure 6: Figure A and B showing wax study models prepared on modeling wax.

that of mandible. The study also reveals traits of sexual dimorphism. The odontometric parameters like number of tooth marks on a bite mark and the width of incisors do not show any significant sexual dimorphism but parameters like arch length and inter canine ratio do show sexual dimorphism where both the arch length and the inter canine ratio is more in males than in females. Therefore, it can be concluded that bite marks found on the crime scene are unique to every individuals. A data base can be maintained for ante mortem records of bite marks and can be used as a tool for biometric identification system.

\section{Acknowledgment}

The Authors would like to express earnest and deepest gratitude to various individuals and organizations where in it would not have been possible to complete my project. Their kind support and help made this project to get successfully completed. I would like to extend my sincere thanks to all of them.

\section{References}

1. Andria LM, Dias JC. Relation of maxillary and mandibular intercuspid width to bizygomatic and bigonial breaths. Angle Orthod. 1978; 48: 154-162.
2. Hemanth $M$, Vidya $M$, Nandaprasad, Bhavana V Karkera. Medico-legal update for sex determination using dental tissue. 2008; 8: 2 .

3. Baume LJ. Physiological tooth migration and its significance for the development of occlusion; the biogenesis of accessional dentition. J Dent Res. 1950; 29: 331-337.

4. Khangura RK, Sircar K, Grewal DS. Four odontometric parameters as a forensic tool in stature estimation. J Forensic Dent Sci. 2015; 7: 132-136.

5. Clark DH. (Ed) 1992, Knight B, 1996. Features of a suspect's dentition useful in bite mark analysis.

6. Fastlicht J. Crowding of mandibular incisors. Am J Orthod. 1970; 58: 156-163.

7. Graber and Swain1998. Current orthodontic principles and practice.

8. Hasan $\mathrm{NH}$. The correlation between certain facial and dental measurements.?

9. Moorrees CFA 1959. The dentition of the growing child, a longitudinal study of dental development between 3 and 18 years of age. Cambridge: Harvard university press.

10. Nidhi Yadav, Prem Chandra Srivastava. Bite Marks: An indispensable forensic odontological evidence in rape cases. J Indian Acad Forensic Med. 2014; 36: 3.

11. Sreedhar G, Sumalatha MN, Ramesh G, Nagarajappa R, Murari A, Agrawal A. Dimorphic mandibular canines in gender determination in Moradabad population of Western Uttar Pradesh. J Forensic Dent Sci. 2015; 7: 32-36.

12. Khezran Qamar, Irfan Ahmed Shaikh, Sajid Naeem: Journal of Ayub medical college Abbottabad. Relationship of the inter-condylar width with mandibular inter-canine width. 2013; 25: 1-2.

13. Knott VB, Meredith HV. Statistics on eruption of the permanent dentition from serial data for North American white children. Angle Orthod. 1966; 36: 68-79.

14. Magne P, Gallucci GO, Belser UC. Anatomic crown width/length ratios of unworn and worn maxillary teeth in white subjects. J Prosthet Dent. 2003; 89: 453-61.

15. Bajpai M, Mishra N, Yadav P, Kumar S. Efficacy of lip prints for determination of sex and inter observer variability. Euro J Exp Bio. 2011; 1: 81-86.

16. Poosti M, Jalai T. Tooth size and arch dimension in in crowded versus crowded class 1 malocclusions. The journal of contemporary dental practice 2007; 3: 045-052.

17. Adeyemi TA, Isiekwe MC. Comparing permanent tooth sizes (mesio-distal) of males and females in a Nigerian population. 2003; West Afr J Med. 2003; 22: $219-221$.

18. That influence dental aesthetics "cephalometric study". Al-Rafidain dentistry journal. 2005; 5: 6-14.

19. Wankhede KP, Bardale RV, Chaudhari GR, Kamdi NY. Determination of sex by discriminant function analysis of mandibles from a central Indian population. J Forensic Dent Sci. 2015; 7: 37-43.

20. Abd-el Samad Younes S. Maxillary arch dimensions in Saudi and Egyptian population sample. Am J Orthod. 1984; 85: 83-8.
Austin J Forensic Sci Criminol - Volume 4 Issue 2 - 2017 ISSN : 2380-0801 | www.austinpublishing group.com Chourasiya et al. () All rights are reserved
Citation: Pagare N, Chourasiya S and Dedhia H. Study of Odontometric Parameters in Gender Identification. Austin J Forensic Sci Criminol. 2017; 4(2): 1060. 